\title{
Radiology
}

\section{Iatrogenic Injuries During Puncture Procedures Applied To Breast}

\author{
Tamara V. Pavlova, MD, PhD ${ }^{1,2}$; Aleksandr Yu. Vasilyev, MD, PhD, $\mathrm{ScD}^{1,3^{*}}$ \\ ${ }^{I}$ Central Research Institute of Radiation Diagnostics \\ ${ }^{2}$ City Clinical Hospital named after V. M. Buyanov \\ ${ }^{3}$ Moscow State University of Medicine and Dentistry named after A. I. Evdokimov \\ Moscow, Russia
}

\begin{abstract}
Background: This article analyzes iatrogenic injuries of the breast that happen during puncture procedures.

Methods and Results: We have analyzed the data of 2075 invasive diagnostic procedures related to both benign and malignant breast neoplasms, conducted in various healthcare facilities in the Russian Federation. There were 1943(93.6\%) cases of ultrasoundguided biopsies in our study. RG-guided biopsies were rather less frequent-132(6.4\%) cases. A subcutaneous hematoma is the primary iatrogenic injury that occurs during breast puncture procedures conducted in Russian healthcare facilities. This is the most common complication during an ultrasound-guided CB (44.4\%). The likelihood that this complication will occur is impossible to predict.

Conclusion: The proper arrangements and patient follow-up before and after the biopsy, along with the selection of a proper invasive procedure for a pathologic neoplasm, will minimize the number of diagnostic iatrogenic injuries and improve the quality of medical care. (International Journal of Biomedicine. 2021;11(1):14-17.)
\end{abstract}

Key Words: breast cancer $\bullet$ fine-needle biopsy $\bullet$ core-biopsy $\bullet$ iatrogeny

For citation: Pavlova TV, Vasilyev AYu. Iatrogenic Injuries During Puncture Procedures Applied To Breast. International Journal of Biomedicine. 2021;11(1):14-17. doi:10.21103/Article11(1)_OA2

\section{Abbreviations}

FNB, fine-needle biopsy; CB, core-biopsy; US, ultrasound; BC, breast cancer

\section{Introduction}

An early diagnosis and effective treatment of breast cancer (BC) are still the key priorities for public healthcare systems in many countries. ${ }^{(1)} \mathrm{As} \mathrm{BC}$ screening programs have been significantly improved, now the specialists are able to identify the malignant tumors in this area at early stages more often. ${ }^{(2,3)}$ It is worth mentioning that most of the detected pathologic changes in the breast are benign; malignant tumors account only for $3 \%-6 \%$ of all cases. ${ }^{(4)}$

The X-ray picture for breast neoplasms is quite variable, which is why any "suspicious" finding, detected by a physical

"Corresponding author: Prof. Alexander Yu. Vasilyev, MD, PhD, ScD. Department of Radiology, Moscow State University of Medicine and Dentistry named after A. I. Evdokimov, Moscow, Russia.E-mail:auv62@mail.ru examination, mammography or an ultrasound scan must be confirmed. ${ }^{(5)} \mathrm{A}$ pathomorphological study is the most accurate way to determine the nature of a pathologic area. The methodology for breast biopsy has been dramatically changed in recent decades. The methods have become more injurious, from fine-needle aspiration biopsy to a vacuum suction type.$^{(6)}$ Regardless of the way biomaterial is obtained, the interventional methods used the for breast may result in such complications as hematomas, Mondor's disease, and acute suppurative mastitis. ${ }^{(7)}$ L.L.Y. Lin et al ${ }^{(8)}$ state that the total amount of complications after breast biopsy does not exceed $6.7 \%$. The most frequent complications are bleedings or hematomas $(89.3 \%)$; breast ache is less frequent $(6.9 \%)$, and dizziness is rare $(0.9 \%)$. A team of scientists supervised by Bick stated that apart from the primary complication, which is a hematoma, in $2 \%-10 \%$ of cases, there may appear the following iatrogenic injuries: infection at a biopsy site 
(4\%-6\%) and abscesses (2\%); the recurrent biopsies are taken as a separate category $(4 \%) .{ }^{(9)}$ Some scientists suppose that a biopsy may increase the risks of a metastatic spread and influence long-term treatment results. ${ }^{(10)}$

All the above-mentioned confirm that it is crucial to study the nature of diagnostic iatrogenic injuries that appear during breast puncture procedures. This study will facilitate further prevention and elimination of such injuries.

\section{Materials and Methods}

We have analyzed the data of 2075 invasive diagnostic procedures related to both benign and malignant breast neoplasms, conducted in various healthcare facilities in the Russian Federation. As for 1784(86.1\%) identified breast pathologies, the biopsies were conducted for medical reasons only (typical semeiotic signs), and in 288(13.9\%) cases female patients were worried and insisted on having a biopsy. In most cases, the patients insisted on having one when the benignant neoplasms under $1.5 \mathrm{~cm}$ (a fibroadenoma or a cyst) were detected for the first time in their lives. During most physical examinations (75.6\%), pathologies of breast and regional lymph nodes were detected manually. In our data, there were 503(24.4\%) non-palpable breast neoplasms. Preliminary statements, depending on the results of breast radial examination, conducted before biopsy, are presented in Table 1.

\section{Table 1.}

Classification of preliminary statements, depending on the results of a radial examination, conducted before a biopsy $(n=2075)$

\begin{tabular}{|l|c|c|}
\hline \multicolumn{1}{|c|}{ Pathology } & Abs. & $\%$ \\
\hline A suspected breast cancer & 348 & 16.8 \\
\hline A cyst (including an inflammatory cyst) & 902 & 43.4 \\
\hline $\begin{array}{l}\text { A fibroadenoma (including a leaf-like } \\
\text { fibroadenoma) }\end{array}$ & 425 & 20.5 \\
\hline Fibrocyatic breast changes & 49 & 2.4 \\
\hline Clustered microcalcifications & 102 & 4.9 \\
\hline Lymphoadenopathy (regional lymph nodes) & 199 & 9.6 \\
\hline Other & 50 & 2.4 \\
\hline
\end{tabular}

"Other" included hematomas, oleogranulomas, fibrolipomas, local fibrosis areas, and tissue architectonic damages.

There were 1943(93.6\%) cases of ultrasound-guided biopsies in our study. G-guided biopsies were rather less frequent-132(6.4\%) cases. The data for the biomaterial sampling method are the following: 1471(70.9\%) pathologic findings were confirmed by a fine-needle aspiration biopsy, 604(29.1\%) cases were confirmed by a needle pistol system that was used to take tissue samples to conduct a histologic or an IHC test, if necessary. These tests can provide more diagnostic data about a pathologic area. The classification of performed puncture procedures, depending on biomaterial sampling and guidance methods, is shown in Fig. 1. Thus, the ultrasoundguided FNB was the most common method of sampling diagnostic material. It was performed in $1455(70.1 \%)$ cases. For $488(23.5 \%)$ cases, an ultrasound-guided CB was chosen. There were $116(5.6 \%)$ stereotaxic CBs, and $16(0.8 \%)$ female patients had to undergo an RG-guided procedure.

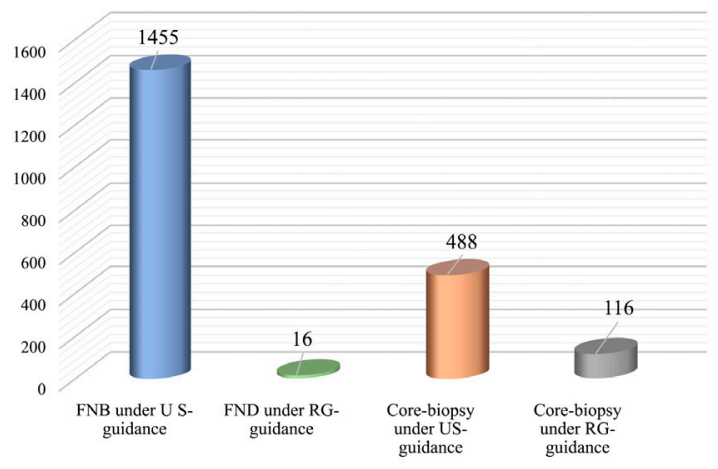

Fig. 1. Classification of performed puncture procedures, depending on biomaterial sampling and guidance methods.

FNB was performed by a "free-hand method" using a standard skewed-ended injection needle with a diameter of $20 \mathrm{G}$, which was connected to a $20 \mathrm{ml}$ syringe. The specialists used to an automatic needle pistol and needles of a guillotine type with a diameter of $14 \mathrm{G}$ to perform a CB. The needle's length varied from $10 \mathrm{~cm}$ to $16 \mathrm{~cm}$, depending on the location of a pathologic area.

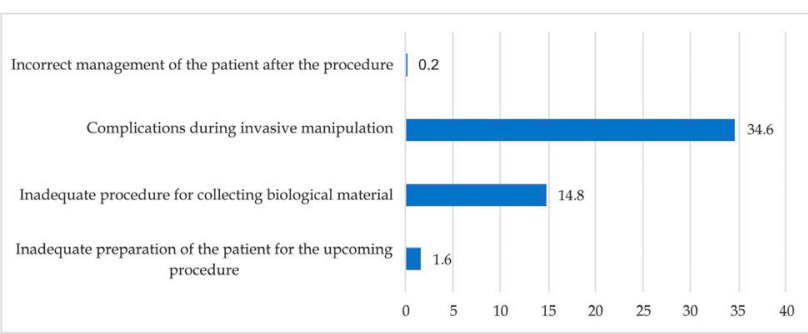

Fig. 2. Classification of faults in medical care provided by radiologists during interventional radiology procedures.

\section{Results and Discussion}

Fig. 2 presents the main faults in medical care provided by radiologists during interventional radiology procedures.

Improper preparation of patients for a biopsy

We were unable to analyze the preparations for all 2075 punctures because 852 procedures had been conducted in other institutions. We have analyzed the data of 1223 puncture biopsies and concluded that patient preparation errors account for $1.6 \%$ of all cases. Seven patients experienced allergic reactions during $\mathrm{CB}$ due to local anesthesia: 5 had hives, and 2 had bronchial spasms. Twelve patients fainted because their blood sugar level was low (they were hungry and stressed).

Improper patient follow-up after the procedure

Three $(0.2 \%)$ patients had complications after an invasive procedure. Two of them had inflammation at the site where the 
biopsy had been taken, and 1 had a chemical skin burn (Fig.3) because the doctor had given her improper instructions regarding the antiseptic treatment of a biopsy needle induction site.

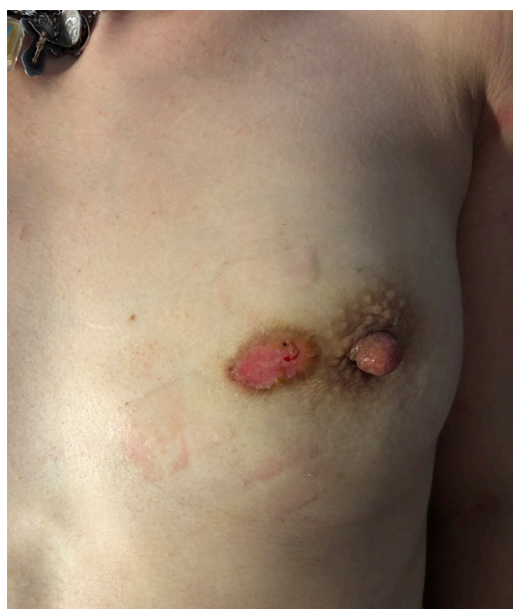

Fig. 3. A female patient's appearance a week after the core biopsy of a neoplasm in the left breast: in the plane where a biopsy needle has been introduced, there is a chemical skin burn, due to iodine solution overuse during wound handling.

\section{Improper biomaterial sampling}

A total of 902(61.3\%) FNBs were conducted because cysts had formed and the diagnostic material had been obtained properly. Although the information value of FNB is not very high in terms of tissue neoplasms, in the rest of the cases (569 [38.7\%]) this biopsy type was used to confirm a significant pathologic area. The conclusion drawn from 274(482\%) cytologic statements was that the obtained material was not informative and that additional invasive procedures were required. As for CBs, 34 out of 604 procedures (5.6\%) were not informative. The tissue "strips" obtained during this invasive procedure had no diagnostic value, so the procedure had to be repeated. Thus, the total amount of cases in which the initial diagnostic material was not informative grew to $308(14.8 \%$ ).

\section{Invasive procedure complications}

Hematomas were the primary complications during invasive diagnostic procedures. They appeared in different time periods after the procedure was conducted (Fig.4). In this study, there were $718(34.6 \%)$ cases with such complications. Table 2 presents the classification of complications, depending on the employed visual control and diagnostic material sampling methods. Thus, subcutaneous hematomas were the most common complications for an ultrasound-guided biopsy (44.4\%). As for an RG-FNB, such complications had the lowest frequency.

Table 2.

Classification of hematomas, detected after breast biopsy, depending on material sampling and guidance methods $(n=718)$

\begin{tabular}{|l|c|c|}
\hline \multicolumn{1}{|c|}{ Biopsy type } & Abs. & $\%$ \\
\hline An ultrasound-guided FNB & 293 & 40.8 \\
\hline A RG-guided FNB & 5 & 0.7 \\
\hline An ultrasound-guided CB & 319 & 44.4 \\
\hline A RG-guided CB & 101 & 14.1 \\
\hline Total & 718 & 100.0 \\
\hline
\end{tabular}

\section{Conclusion}

A subcutaneous hematoma is the primary iatrogenic injury that occurs during breast puncture procedures conducted in Russian healthcare facilities. This is the most common complication during an ultrasound-guided CB (44.4\%). The likelihood that this complication will occur is impossible to predict. However, proper arrangements and patient follow-up before and after the biopsy, along with the selection of a proper invasive procedure for a pathologic neoplasm, will minimize the number of diagnostic iatrogenic injuries and improve the quality of medical care.
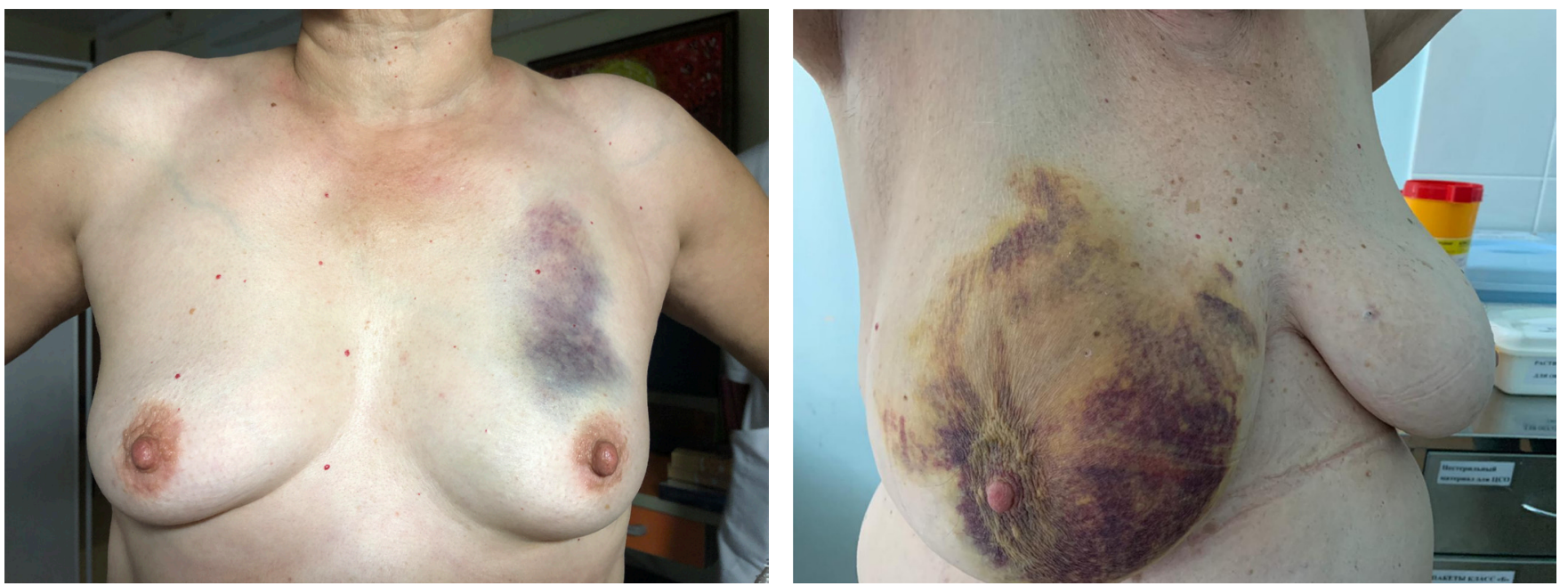

Fig. 4. The appearance of a female patient, who had hematomas after a core biopsy: a) 8 days after an ultrasound-guided CB of a neoplasm in the left breast: at the border of upper quadrants, there is a subcutaneous hematoma; b) 12 days after a RG-guided CB of clustered calcifications in the right breast, there is a spread subcutaneous hematoma, which occupies most of the gland. 


\section{Competing Interests} interests.

The authors declare that they have no competing

\section{References}

1. Bray F, Ferlay J, Soerjomataram I, Siegel RL, Torre LA, Jemal A. Global cancer statistics 2018: GLOBOCAN estimates of incidence and mortality worldwide for 36 cancers in 185 countries. CA Cancer J Clin. 2018 Nov;68(6):394-424. doi: $10.3322 /$ caac. 21492 .

2. Rana C, Ramakant P, Babu S, Singh K, Mishra A, Mouli S. Unusual Breast Neoplasm with Diagnostic and Management Challenges. Indian J Surg Oncol. 2018 Sep;9(3):328-335. doi: 10.1007/s13193-018-0781-3.

3. Yaffe MJ, Mittmann N, Alagoz O, Trentham-Dietz A, Tosteson AN, Stout NK. The effect of mammography screening regimen on incidence-based breast cancer mortality. J Med Screen. 2018 Dec;25(4):197-204. doi: 10.1177/0969141318780152.

4. Stachs A, Stubert J, Reimer T, Hartmann S. Benign Breast Disease in Women. Dtsch Arztebl Int. 2019 Aug 9;116(3334):565-574. doi: 10.3238/arztebl.2019.0565.

5. Salzman B, Collins E, Hersh L. Common Breast Problems. Am Fam Physician. 2019 Apr 15;99(8):505-514. PMID: 30990294.
6. Bennett IC, Saboo A. The Evolving Role of Vacuum Assisted Biopsy of the Breast: A Progression from Fine-Needle Aspiration Biopsy. World J Surg. 2019 Apr;43(4):1054-1061. doi: 10.1007/s00268-018-04892-x.

7. Suganthan N, Ratnasamy V. Mondor's disease - a rare cause of chest pain: a case report. J Med Case Rep. 2018 Jan 9;12(1):4. doi: 10.1186/s13256-017-1530-X.

8. Lin LLY, Gao Y, Lewin AA, Toth HK, Heller SL, Moy L. Overstated Harms of Breast Cancer Screening? A Large Outcomes Analysis of Complications Associated With 9-Gauge Stereotactic Vacuum-Assisted Breast Biopsy. AJR Am J Roentgenol. 2019 Apr;212(4):925-932. doi: 10.2214/ AJR.18.20421.

9. Bick U, Trimboli RM, Athanasiou A, Balleyguier C, Baltzer PAT, Bernathova M, et al.; European Society of Breast Imaging (EUSOBI), with language review by Europa DonnaThe European Breast Cancer Coalition. Image-guided breast biopsy and localisation: recommendations for information to women and referring physicians by the European Society of Breast Imaging. Insights Imaging. 2020 Feb 5;11(1):12. doi: 10.1186/s13244-019-0803-X.

10. Kong YC, Bhoo-Pathy N, O’Rorke M, Subramaniam S, Bhoo-Pathy NT, See MH, Jamaris S, Teoh KH, Bustam AZ, Looi LM, Taib NA, Yip CH. The association between methods of biopsy and survival following breast cancer: A hospital registry based cohort study. Medicine (Baltimore). 2020 Feb;99(6):e19093. doi: 10.1097/MD.0000000000019093. 